Superalloys 2012: 12 ${ }^{\text {th }}$ International Symposium on Superalloys

\title{
DWELL NOTCH LOW-CYCLE FATIGUE PERFORMANCE OF POWDER METAL ALLOY 10
}

\author{
Dan Greving, Pete Kantzos, Jim Neumann, Derek Rice and Harry Kington \\ Honeywell Engines, 111 South 34th St., Phoenix, AZ 85034, USA
}

Keywords: P/M Superalloy, Alloy 10, dwell fatigue, creep, grain boundary oxidation, crack closure

\begin{abstract}
Alloy 10 is a third generation powder metal nickelbased superalloy developed by Honeywell for higher temperature turbine and compressor disk applications. Turbine disk blade attachments experience concentrated stresses at elevated temperatures for extended periods of time. Therefore, the notch dwell fatigue capability of an alloy is critical in determining the durability of a turbine disk. A dwell notch lowcycle fatigue (LCF) program was conducted to assess the high temperature capability of Alloy 10 under different geometric stress concentration conditions. The initial intent was not to significantly revise or develop new life prediction methods, but to determine practical operating conditions and temperature limits that minimize the detrimental effects of sustained peak loading. The test program consisted of uniaxially loaded flat double edge notch specimens with geometric stress concentration factors (Kt) of 2 and 3 evaluated under various sustained peak loading conditions. The Kt 2 and 3 specimens were selected to represent the range of stress gradients for turbine disk blade attachment locations. The test temperatures ranged from $650^{\circ} \mathrm{C}$ to $704^{\circ} \mathrm{C}$ with a typical peak tensile hold time of 90 seconds. Conventional non-dwell notch fatigue and creep rupture tests were also conducted to determine baseline properties. An elastic/plastic finite element model with additional creep visco-plasticity was also developed to better understand the potential mechanisms that influence fatigue crack initiation. The empirical and analytical results indicate that stress gradient, creep-induced stress relaxation, cyclic stress state, and environmental factors such as oxidation-assisted crack closure contribute to the elevated temperature dwell fatigue performance of Alloy 10.
\end{abstract}

\section{Introduction}

Nickel-based superalloys are used for turbine and high pressure compressor disk applications due to their ability to maintain mechanical properties at elevated temperatures. As aero-engines continue to develop, there is ever increasing thermal demands on the materials used for turbine and compressor disks. An alloy's response to environmental and temperature conditions under sustained peak loading or dwell conditions is a significant concern for assessing actual in-service capability. Practical temperature limits exist where environmental as well as material changes become significant factors in performance at elevated conditions. Metal temperatures at concentrated stress locations such as blade attachments are routinely in excess of $650^{\circ} \mathrm{C}$ on new designs. This temperature level exceeds practical operating limits for many conventional cast and wrought superalloys due to detrimental dwell effects. Third generation powder metals, like Alloy 10, are intended to extend the operating temperature capability of a component above that achieved with conventional cast and wrought superalloys [1].
New highly reliable life prediction systems are required as metal temperatures increase and dwell effects become dominant [2]. Fatigue and creep interactions have been the traditional failure modes considered active under dwell fatigue conditions [3]. It is becoming more evident that oxidation also plays a key role, specifically grain boundary oxidation [4]. There is even evidence that the grain boundary oxidation observed under cyclic dwell conditions is stress accelerated [5, 6, and 7]. Therefore, it is not sufficient to have highly creep/fatigue resistant materials for elevated temperature application. Alloys engineered for better grain boundary oxidation resistance are essential to meet the dwell effect demands.

A notch dwell fatigue program was conducted to assess the high temperature capability of Alloy 10. The initial intent was not to significantly revise or develop new life prediction methods, but to determine practical operating conditions and temperature limits that minimize the detrimental effects of dwell or sustained peak loading. The empirical and analytical results indicate that creep, initial stress gradient, and grain boundary oxidation are critical to Alloy 10's dwell fatigue capability.

\section{Material}

The Alloy 10 powder material used for the test program was argon-atomized and hot-istostatic-pressure (HIP) compacted to a 24 to $29 \mathrm{~cm}$ diameter billet. The alloy is vacuum-induction-melted (VIM) prior to atomization. The powder is then sieved to -270 mesh ( -53 micron) and loaded into stainless steel containers prior to HIP. Billet sections of approximately 6 to $9 \mathrm{~cm}$ thickness were then solutioned above the gamma prime precipitate solvus temperature and quenched into a $650^{\circ} \mathrm{C}$ salt bath after a controlled time delay. A uniform grain size of approximately ASTM 8 was achieved with this heat treatment. The salt bath quench is performed to control cooling rates at critical sections for improved mechanical properties. The material was then given a typical stabilization and aging heat treatment cycle. Table 1 lists the nominal composition of Alloy 10 [8]. Figure 1 shows the typical microstructure of the Alloy 10 material after final heat treatment. The heat treatment produced a minimal amount of grain boundary serrations. Figure 2 shows the typical cooling gamma prime $\left(\gamma^{\prime}\right)$ structure in the rim section of the Alloy 10 billet. The median cooling gamma prime size is approximately $280 \mathrm{~nm}$. Specimens for the notch dwell tests were all removed from the rim section of the billet since this is the location and microstructure most likely to experience elevated temperatures and dwell effects. 
Table 1. Nominal chemistry of Alloy 10.

\begin{tabular}{|c|c|c|c|c|c|}
\hline $\mathbf{W}$ & $\mathbf{T a}$ & $\mathbf{M o}$ & $\mathbf{N b}$ & $\mathbf{C r}$ & $\mathbf{N i}$ \\
\hline 4.5 & 2 & 2.7 & 1.1 & 11.5 & $\mathrm{Bal}$ \\
\hline Co & $\mathrm{Ti}$ & $\mathbf{A l}$ & $\mathbf{C}$ & $\mathbf{B}$ & $\mathbf{Z r}$ \\
\hline 18.5 & 4 & 3.75 & 0.03 & 0.03 & 0.07 \\
\hline
\end{tabular}

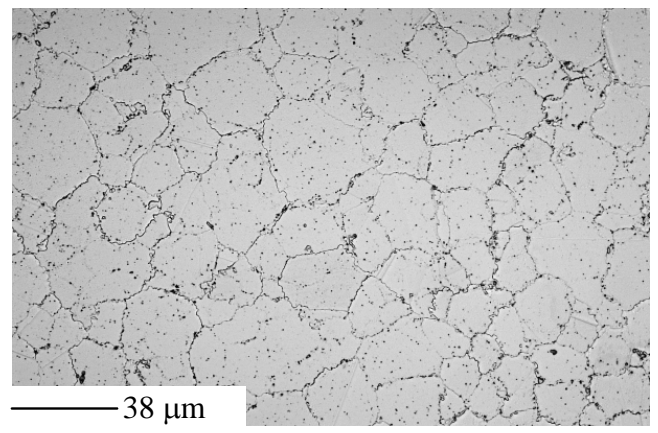

Figure 1. Typical microstructure of Alloy 10.

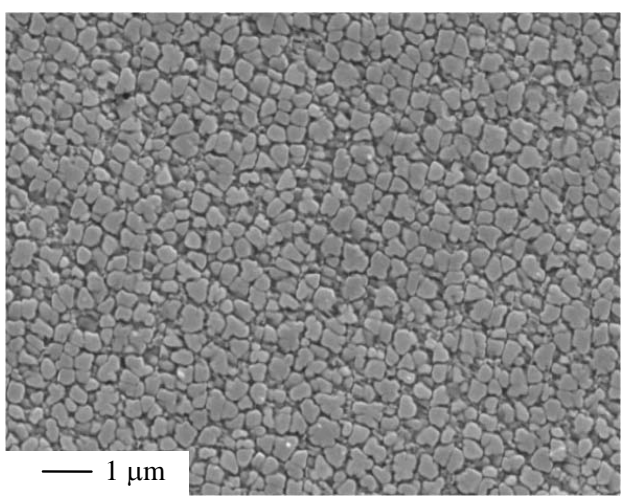

Figure 2. Cooling gamma prime structure of Alloy 10.

\section{Notch Fatigue Specimen and Test Conditions}

A flat double edge notch specimen was selected to initially characterize the dwell behavior of Alloy 10 . Notch root radii of $0.203 \mathrm{~cm}$ and $0.056 \mathrm{~cm}$ were chosen to represent geometric stress concentrations (Kt) of 2 and 3 respectively. The Kt's of 2 and 3 were selected since they represent a range of stress gradients typical for turbine disk attachment or firtree designs. The specimen used for dwell testing is shown in Figure 3. Figure 4 compares the elastic stress gradients for the Kt 2 and Kt 3 specimens. The y-axis in Figure 4 is the maximum principal stress. Note that the $1380 \mathrm{MPa}$ notch root peak stress is shown for reference and does not represent an actual test condition. The $\mathrm{x}$-axis is distance from the notch surface in mm. Specimen notches were all manufactured using low stress grinding. A longitudinal polish was used for the final finish to simulate the surface requirements for smooth bar LCF specimens. Residual stresses at the notch are expected to be near neutral and the surface finish $\left(\mathrm{R}_{\mathrm{a}}\right)$ is approximately 32 micro-inch $(0.8 \mu \mathrm{m})$.

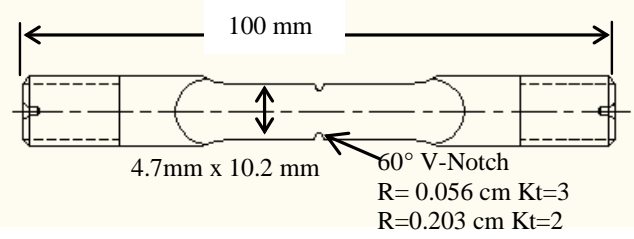

Figure 3. Illustration of notch fatigue specimen.

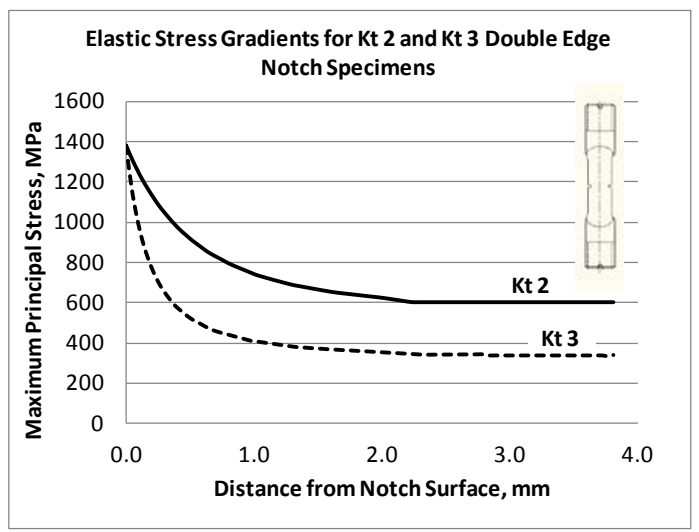

Figure 4. Elastic stress gradient comparison of Kt 2 and Kt 3 specimens.

All testing was conducted on uniaxial closed-loop servo-hydraulic fatigue test frames. Heating was achieved by resistance furnaces. Testing consisted of a load control sinusoidal pattern for non-dwell cycles. For dwell cycles, a 90second hold at the tensile peak stress was used. It is understood that the 90-second hold is a minimum time for environmental effects to become active and allows the least amount of potentially beneficial creep relaxation during the initial cycling. All tests were run at a net section stress ratio $R_{\text {load }}$ of 0.05 . Table 2 lists the test matrix developed for this program. Tests without dwell were conducted at the same stress and temperature conditions for direct comparison to the dwell specimen lives.

Table 2. Dwell Alloy 10 notch fatigue matrix.

\begin{tabular}{|c|c|c|c|c|}
\hline$K \mathrm{t}$ & Temp, C & $\begin{array}{l}\text { Elastic Notch } \\
\text { Root Stress } \\
\text { Range, MPa }\end{array}$ & $\begin{array}{c}\text { No. } \\
\text { Samples }\end{array}$ & $\begin{array}{c}\text { Hold } \\
\text { Time, sec }\end{array}$ \\
\hline 2 & 650 & 1863 & 4 & 90 \\
\hline 3 & 650 & 1794 & 5 & 90 \\
\hline 2 & 680 & 1725 & 4 & 90 \\
\hline 3 & 680 & 1725 & 6 & 90 \\
\hline 2 & 704 & 1656 & 5 & 90 \\
\hline 3 & 704 & 1656 & 4 & 90 \\
\hline
\end{tabular}

Notch Fatigue Results

Figures 5 through 7 compare dwell and non-dwell Kt 2 and 3 notch LCF probability plots of the $650^{\circ} \mathrm{C}, 680^{\circ} \mathrm{C}$, and $704^{\circ} \mathrm{C}$ test results respectively. The $\mathrm{x}$-axis in Figures 5 through 7 is total cycles to failure and the y-axis is the cumulative 
distribution function (CDF) or proportion of failures. Figures 5 through 7 are useful for comparing the relative fatigue lives and scatter between the dwell and non-dwell specimens tested at the same stress and temperature. Figure 8 shows the average life comparisons for Kt 2 and Kt 3 dwell and non-dwell specimens. The y-axis in Figure 8 is total cycles to failure.

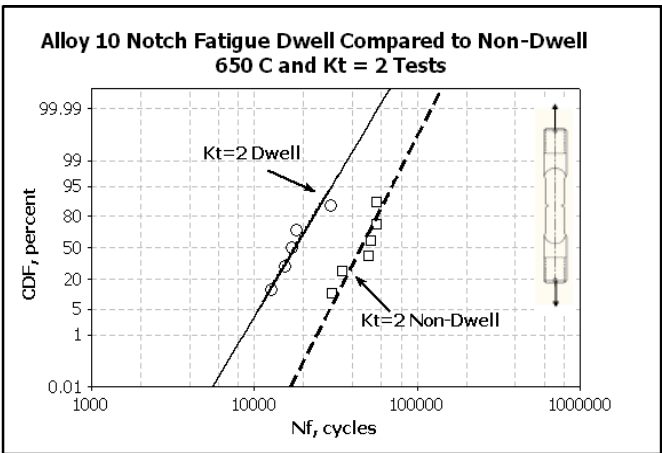

a) $\mathrm{Kt}=2,650^{\circ} \mathrm{C}$.

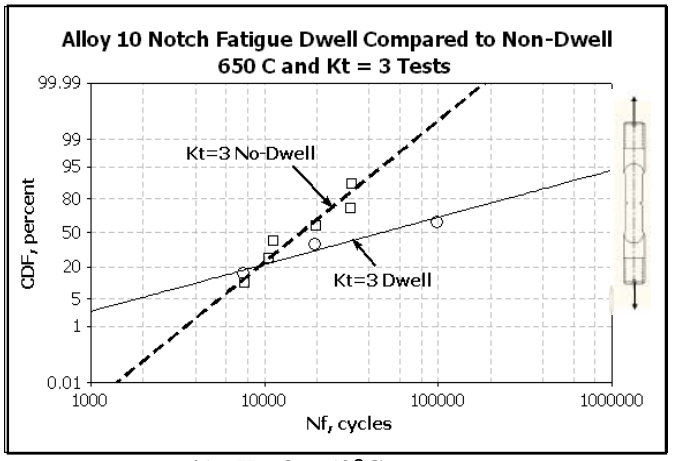

b) $\mathrm{Kt}=3,650^{\circ} \mathrm{C}$.

Figure 5. Probability plots comparing dwell and non-dwell notch fatigue results at $650^{\circ} \mathrm{C}$ for a) $\mathrm{Kt}=2$ and b) $\mathrm{Kt}=3$.

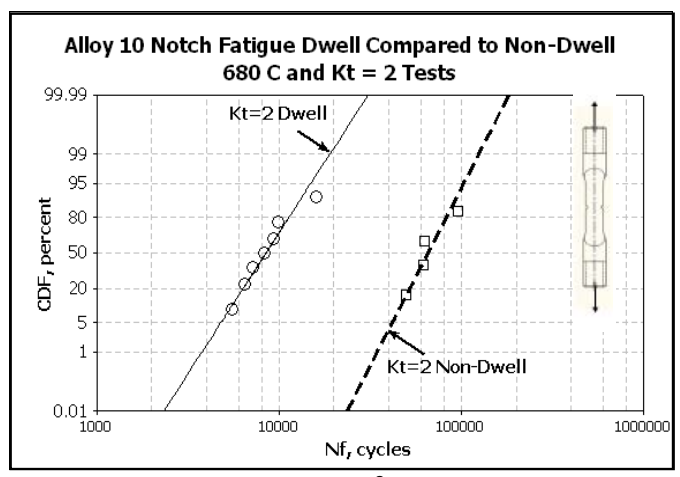

a) $\mathrm{Kt}=2,680^{\circ} \mathrm{C}$.

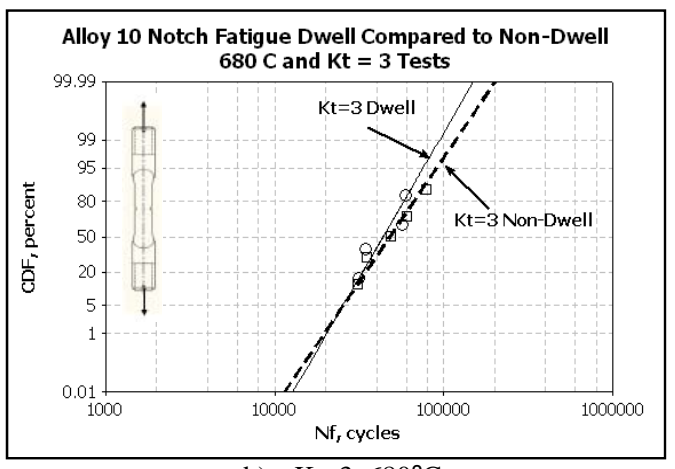

b) $\mathrm{Kt}=3,680^{\circ} \mathrm{C}$.

Figure 6. Probability plots comparing dwell and non-dwell notch fatigue results at $680^{\circ} \mathrm{C}$ for a) $\mathrm{Kt}=2$ and b) $\mathrm{Kt}=3$.

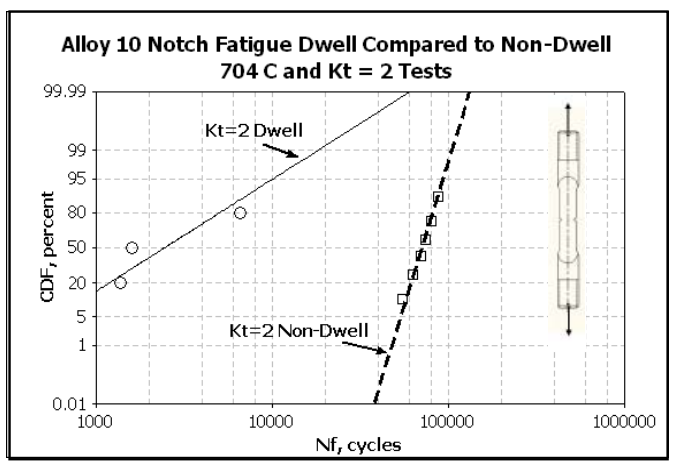

a) $\mathrm{Kt}=2,704{ }^{\circ} \mathrm{C}$

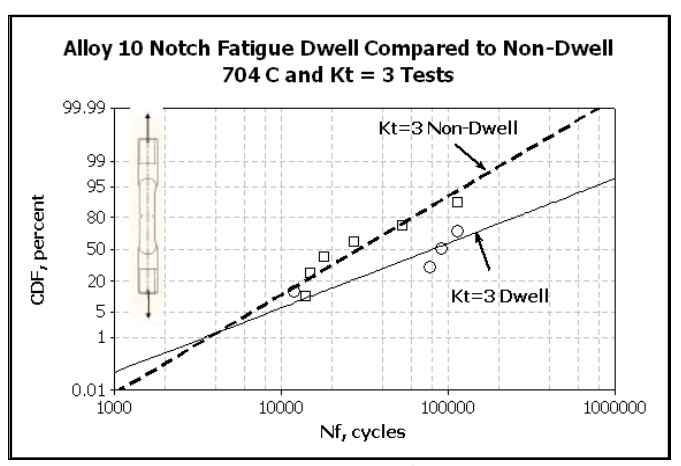

b) $\mathrm{Kt}=3,704^{\circ} \mathrm{C}$.

Figure 7. Probability plots comparing dwell and non-dwell notch fatigue results at $704^{\circ} \mathrm{C}$ for a) $\mathrm{Kt}=2$ and b) $\mathrm{Kt}=3$. 


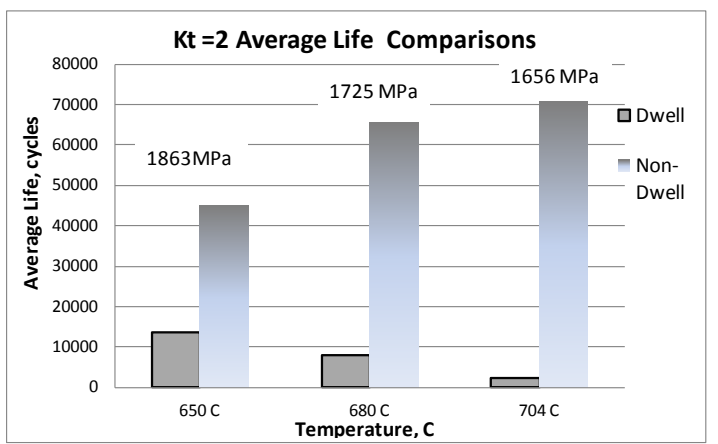

a) $\mathrm{Kt}=2$ Average lives $650^{\circ} \mathrm{C}, 680^{\circ} \mathrm{C}$, and $704^{\circ} \mathrm{C}$.

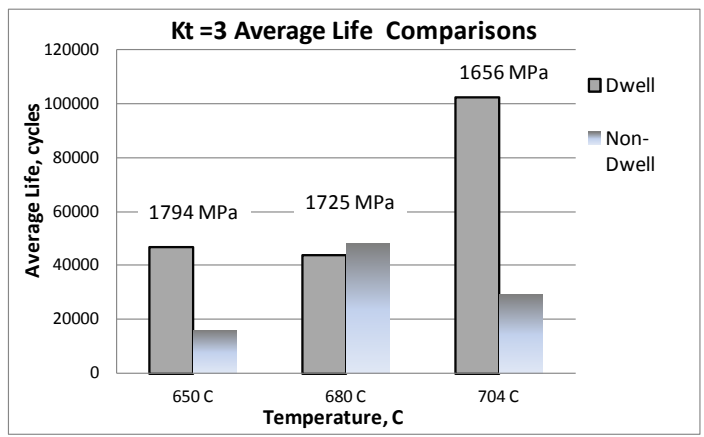

b) $\mathrm{Kt}=3$ Average lives $650^{\circ} \mathrm{C}, 680^{\circ} \mathrm{C}$, and $704^{\circ} \mathrm{C}$.

Figure 8. Alloy 10 average notched dwell LCF behavior compared to baseline a) $\mathrm{Kt}=2 \mathrm{~b}$ ) $\mathrm{Kt}=3$.

Figures 5 through 8 illustrate that there is a distinct separation in dwell LCF performance between the Kt 2 and Kt 3 specimens. For most cases, the $\mathrm{Kt} 3$ specimens showed improved dwell fatigue total lives relative to baseline non-dwell results. From an average life basis, the delta improvement in Kt 3 dwell life relative to non-dwell appears to increase with the highest test temperature. Conversely, the Kt 2 dwell specimens failed at significantly lower lives when compared to baseline non-dwell results. From an average life basis, the delta decrease in Kt 2 dwell life relative to non-dwell becomes greater as temperature increases.

For the Kt $3650^{\circ} \mathrm{C}$ condition, the scatter in the dwell data is significantly higher than for the other test conditions. This is the result of a single lower life specimen result. A review of the fractography and test records indicated no anomalies. Therefore, the lower life result is included and may be indicative of the scatter inconsistencies observed in dwell fatigue tests [9]. Detailed fractography also revealed consistent and similar failure modes for both the Kt 2 and Kt 3 specimens.

\section{Fractography and Grain Boundary Oxidation}

For both Kt 2 and Kt 3 dwell cases, cracks nucleated at surface-connected grain boundaries oriented perpendicular to the maximum principle stress and were associated with localized oxidation. After this intergranular crack initiation mechanism occurs, the subsequent remaining life is spent in mixed mode intergranular and transgranular crack propagation. The secondary electron images in Figure 9 show an example initiation site for a Kt $2650^{\circ} \mathrm{C}$ dwell specimen. Figure 9 also shows a higher magnification view of an "oxide blister" on the notch surface. These "oxide blisters" are prevalent along the high stress notch root regions on both Kt 2 and Kt 3 specimens. Lower stress regions at the same temperature do not show evidence of preferential grain boundary oxide formation. The series of micrographs in Figure 10 show a cross section through several "oxide blisters" near a notch root failure site. Figure 10 illustrates that the oxide blisters are almost always associated with a grain boundary that is relatively perpendicular to the maximum principal stress in the notch. Grain boundaries intersecting the notch root surface at oblique angles to the maximum principal stress show minimal evidence of intergranular oxidation. The formation of these oxides on preferential grain boundaries perpendicular to the maximum principal stress indicates that the oxygen diffusion process into the material is highly dependent upon stress acceleration.

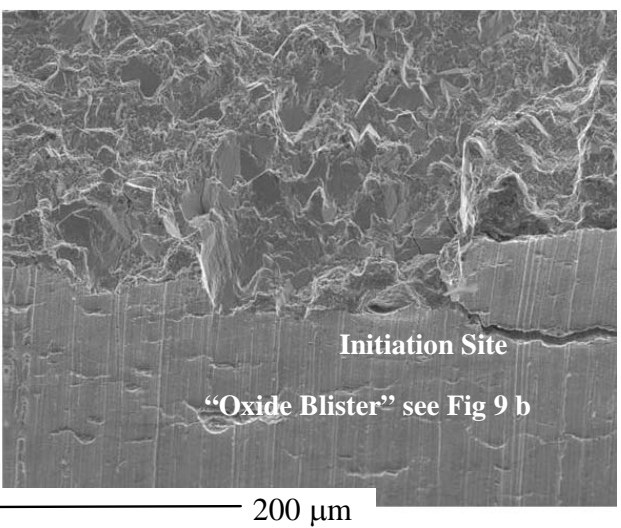

a) Intergranular initiation site at notch root center.

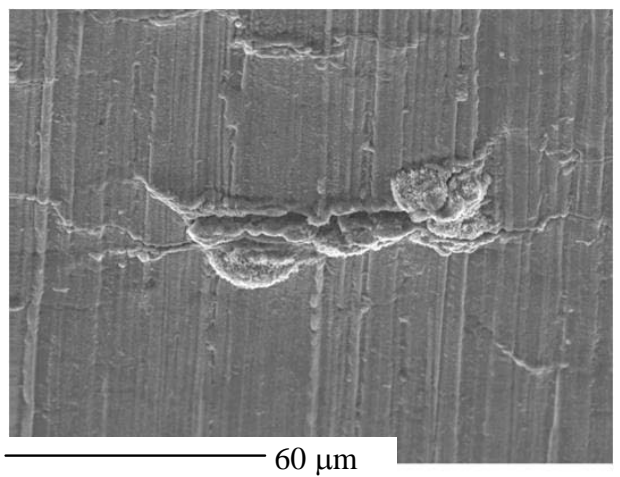

b) “Oxide Blister” on high stress notch root radius.

Figure 9. Example Kt $2650^{\circ} \mathrm{C}$ dwell specimen fractography a) initiation site and b) view of preferential grain boundary oxidation in the form of surface "oxide blister". 


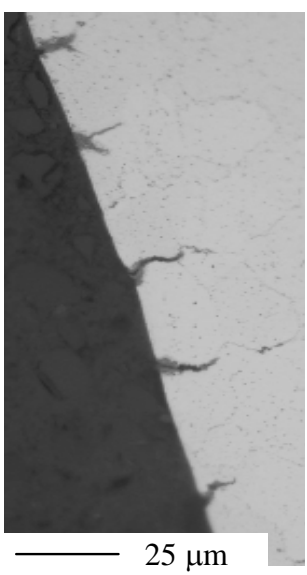

a)

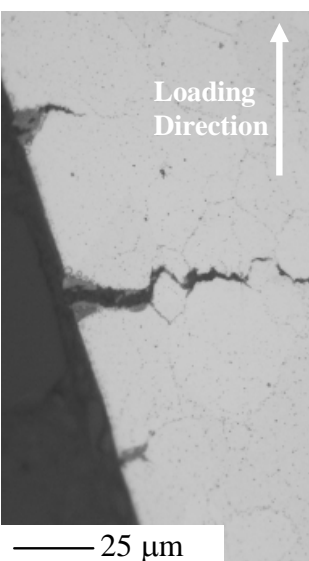

b)
Figure 10. Optical images a) typical dwell fatigue initiation sites in Alloy $10 \mathrm{Kt} 2$, b) showing grain boundary oxidation sites associated with "oxide blisters".

Note that all non-dwell Kt 2 and Kt 3 specimens initiated cracks on crystallographic facets near the notch root surface. Figure 11 shows a secondary electron image of an example non-dwell initiation site for a $\mathrm{Kt}=2650^{\circ} \mathrm{C}$ specimen. The non-dwell specimens also showed minimal evidence of grain boundary oxidation.

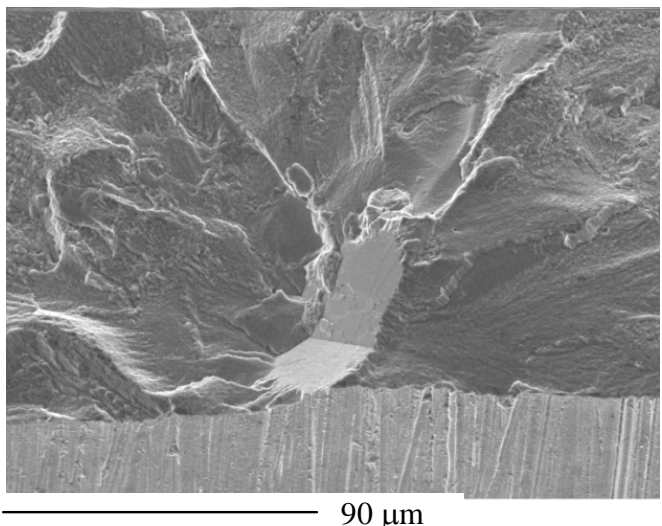

Figure 11. Example Kt $2650^{\circ} \mathrm{C}$ non-dwell specimen fractography showing typical near surface crystallographic facetted initiation.

Figure 12 shows an example microprobe element line scans across an oxidized surface-connected grain boundary. The specimen in Figure 12 is a $\mathrm{Kt} 3704^{\circ} \mathrm{C}$ run-out with over 150,000 dwell cycles. This Kt 3 run-out dwell specimen has approximately 5 times greater life than an average non-dwell specimen at the same stress and temperature. The oxidized grain boundaries are typically enriched with $\mathrm{Cr}, \mathrm{W}, \mathrm{Al}$ and $\mathrm{Ti}$ with $\mathrm{Ni}, \mathrm{Mo}$, and Co showing varying levels of depletion or enrichment relative to the baseline. Similar results for RR1000 were observed by Karabela, et. al. [4]. The formation of brittle $\mathrm{Cr}_{2} \mathrm{O}_{3}, \mathrm{TiO}_{2}$, and $\mathrm{NiO}$ oxides and penetration of oxygen into the material along grain boundaries leads to detrimental effects on fatigue life. Therefore, the formation of these brittle oxides along grain boundaries provides supporting information for the significantly decreased capability displayed by the Kt 2 dwell fatigue specimens.

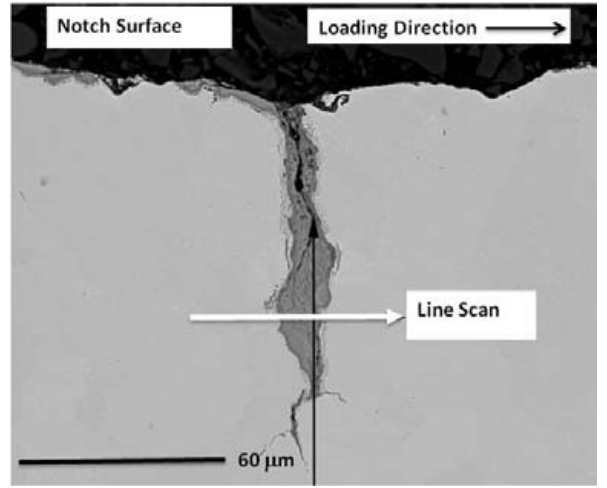

a)
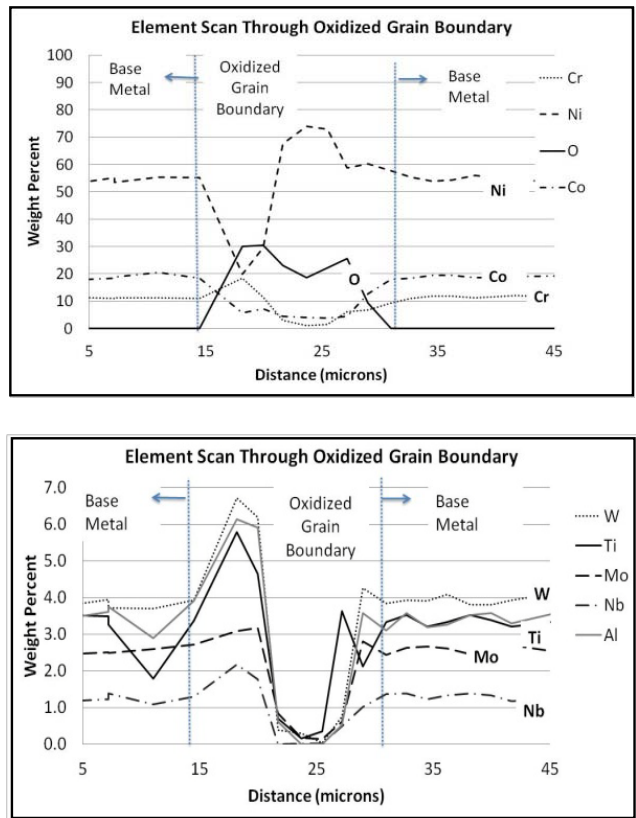

b)

Figure 12. Microprobe line scans across an oxidized grain boundary on a $704{ }^{\circ} \mathrm{C} \mathrm{Kt} 3$ run-out specimen a) Backscattered electron image of polished sample showing an oxidized grain boundary used for the element line scan in b)

From a failure mode perspective, it appears that cracked grain boundaries develop early in the fatigue life through stress accelerated grain boundary oxidation. This mechanism was observed regardless of specimen (Kt 2 or Kt 3 ). Since the Kt 3 specimens generally have superior dwell performance, other mechanisms must be considered which can offset the detriment caused from the grain boundary oxidation. Based on the amount of grain boundary oxidation present in the Kt 3 run-out specimen shown in Figure 12, the intergranular crack initiation mechanism started early but further extension was arrested. Thus, potential factors such as creep relaxation and/or oxide- 
induced crack closure are likely contributors to the final notch dwell fatigue performance.

\section{Creep Relaxation}

ANSYS-implicit creep analyses were used to predict the visco-plastic creep-related stress relaxation that can occur during dwell. All analyses were run to a cumulative hold time of 100 hours which represent approximately 4,000 dwell cycles. The Alloy 10 tensile and creep rate properties were generated from specific tests conducted on material from the same powder and heat treat lots. Cyclic mechanical plasticity is also included in the analysis. The analyses were conducted by first simulating the plasticity from the pure mechanical load followed by creep from a peak load hold for a specified dwell time. The analysis then continues by unloading to the minimum net section load (given $\mathrm{R}_{\text {load }}=0.05$ ), followed by a re-application of the peak load and a dwell hold. The stress distributions immediately after re-load are the ones reported in this document. Figure 13 illustrates the loading profile used in the analyses. The loading cycle was selected as a practical balance of computer run-time and simulated behavior. The authors acknowledge that this does not fully represent the continuous 90 second dwell cyclic conditions but is an acceptable approximation. Figures 14 and 15 show the predicted time-dependent peak stress relaxation that occurs at a temperature of $680{ }^{\circ} \mathrm{C}$ for Kt 2 and Kt 3 specimens respectively. The $680^{\circ} \mathrm{C}$ results are shown as an example to illustrate the predicted creep effects. The $650^{\circ} \mathrm{C}$ and $704^{\circ} \mathrm{C}$ results are similar to those shown in Figures 14 and 15 . The yaxis in Figures 14 and 15 represents the maximum principal stress. The $\mathrm{x}$-axis is distance from the notch root surface in $\mathrm{mm}$. Figures 16 and 17 show the Kt 2 and Kt 3 accumulated creep strain for the $680^{\circ} \mathrm{C}$ simulation respectively. The y-axis in Figures 16 and 17 represents the strain in percentage that is only attributed to creep.

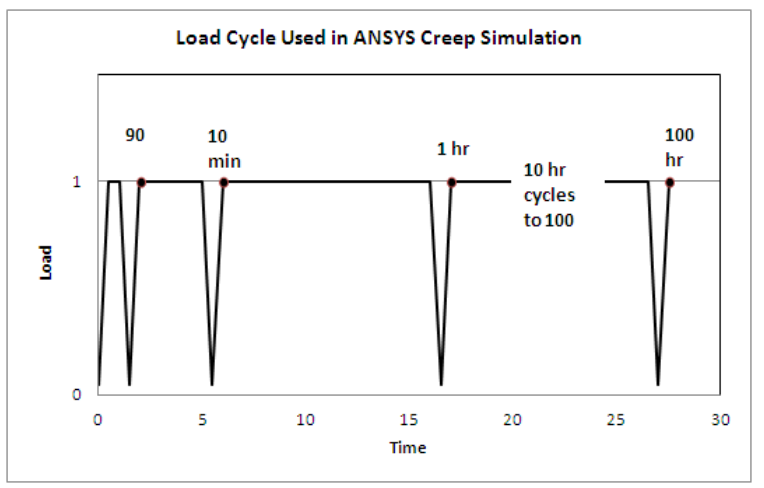

Figure 13. Illustration of the load cycle used in creep simulations.

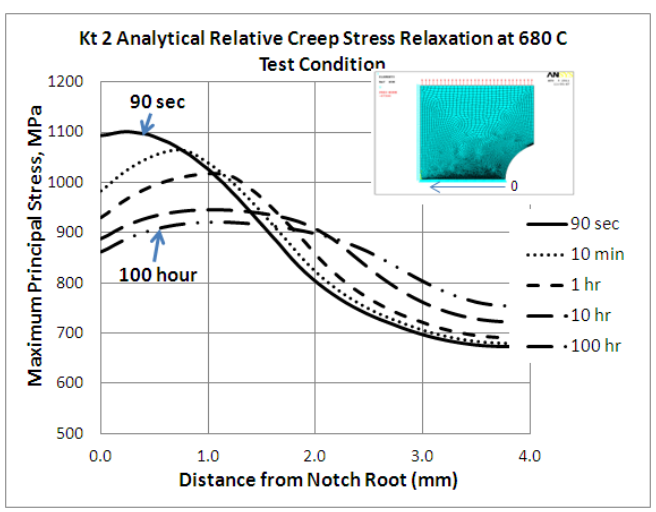

Figure 14. Predicted creep-induced stress relaxation / redistribution from notch surface to center for a Kt 2 specimen at $680^{\circ} \mathrm{C}$.

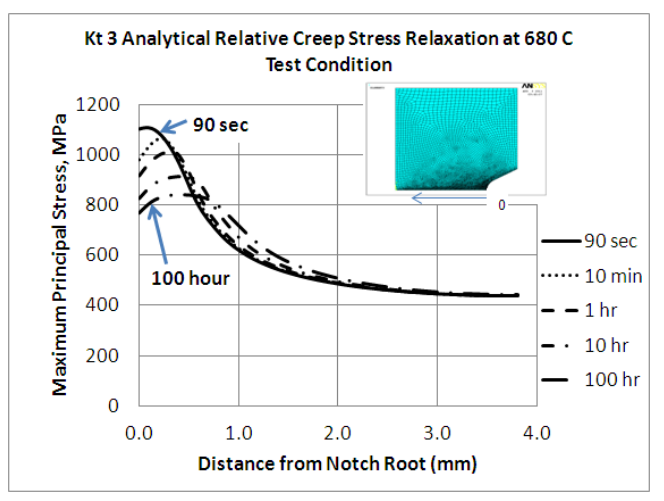

Figure 15. Predicted creep-induced stress relaxation from notch surface to center for a Kt 3 specimen at $680^{\circ} \mathrm{C}$.

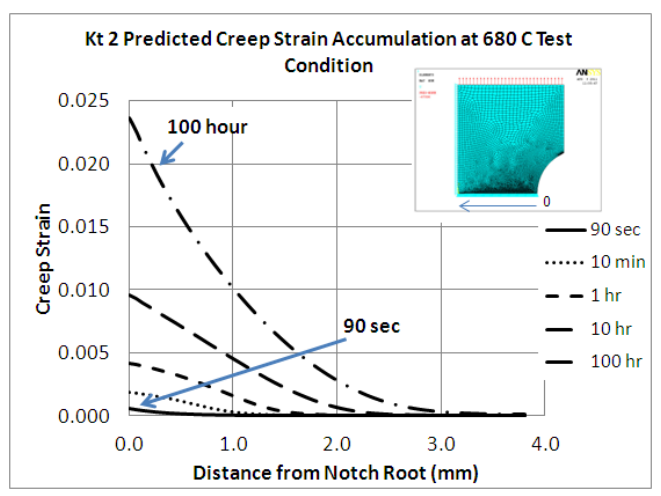

Figure 16. Predicted accumulated creep strain from notch surface to center for a Kt 2 specimen at $680^{\circ} \mathrm{C}$. 


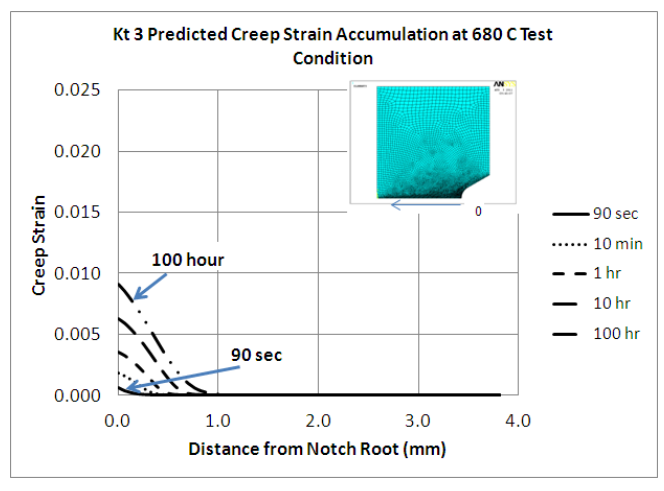

Figure 17. Predicted accumulated creep strain from notch surface to center for a Kt 3 specimen at $680^{\circ} \mathrm{C}$.

The analyses for all three temperatures consistently predict a greater percentage of near surface stress relaxation for the Kt 3 geometry past 1 hour of hold time. However, the Kt 2 specimen appears to have a reduced rate of near surface relaxation after 1 hour. The Kt 2 specimen reaches a point of saturation near the surface followed by net section creep that starts to equalize the stress from notch surface to center. The most significant finding for the Kt 2 specimen is that the background net section stress does not relax but actually increases with time and temperature. Jiang, et. al. found similar analytical creep prediction results for circumferential notch specimens [10]. The increasing background stress for a Kt of 2 is a result of bulk stress redistributions from large scale creep deformation that accumulates during the unload and load dwell cycles. The corresponding creep strains shown for a Kt 2 specimen in Figure 16 illustrate that regions near the notch are transitioning from a secondary to a tertiary creep regime between 10 and 100 hours. Figure 16 also shows that plastic strains from creep are accumulating through the net section of the Kt 2 specimen after the first hour of dwell time. The transiting creep and net section creep deformation will act to accelerate the creep damage accumulation and subsequent failure. The increasing background stresses, accelerated creep damage, and grain boundary oxidation combine to produce the significant Kt 2 dwell fatigue debit. The analyses also demonstrate that for Kt 2 the creep damage should increase at higher temperatures. This supports the empirical observation shown in Figure 8 where dwell fatigue performance of the Kt 2 specimen shows a greater delta in average life relative to nondwell as temperature increases.

Figures 15 and 17 show that for the Kt 3 specimen notch root, stress relaxation is steady and creep strains remain in a steady secondary creep rate condition. The Kt 3 specimen also shows no background net section creep strain or stress redistribution for the time analyzed. The analyses of Kt 3 specimens provide supporting evidence that the grain boundary crack nucleation process can start early but the onset of creep relaxation helps mitigate the detrimental effects. However, even with creep relaxation, cracks should nucleate and propagate on oxidized grain boundaries resulting in a generally lower life relative to non-dwell. Since this is not the case for Kt 3, other mechanisms are arresting the crack. The authors propose that the cracks on the grain boundaries eventually "pack" with oxides, which provide a decelerating closure effect. This oxideinduced crack closure effect combined with creep stress relaxation reduces and in some cases arrest subsequent propagation. It is also understood that for a Kt 3 stress gradient, performance actually improves with higher temperatures where creep relaxation and oxidation for crack closure are accelerated. The empirical data shown in Figure 8 supports this contention. This would only be valid up to the point where temperatures create excessive creep and oxidation damage that exceed the benefits.

\section{Discussion}

The reason for the dramatic difference in performance between Kt 2 and Kt 3 was not initially apparent to the authors since both specimen types experience the same grain boundary oxidation crack nucleation mechanism. The analytical creep stress results were essential to understanding the difference in behavior. Once a grain boundary starts to oxidize and nucleate a crack, the subsequent propagation behaves differently based on the influence of the local creep relaxation. The steeper stress gradient of the Kt 3 specimen has the ability to creep relax local stresses more effectively than the shallower gradient for Kt 2 . The authors suggest that the creep-relaxed near surface stress, in combination with oxide-induced crack closure, improves the apparent dwell fatigue life of the Kt 3 specimens.

Dwell fatigue failure mechanisms like those observed in this study present challenges for higher temperature turbine disk attachment designs. A creep-relaxed crack closure threshold approach to managing fatigue life is not a reliable method for predicting the durability of components given the higher potential scatter sometimes observed in dwell testing. There is also the reality of multiple mode initiation mechanisms that can occur in the field. The high degree of scatter observed in some notch dwell tests is attributed to the inconsistent nature of this mechanism. These effects are not well understood and still need to be quantified through extensive testing.

The conventional approach is to develop designs that do not operate above stress and temperature limits where deleterious dwell effects occur. This is not a practical approach for future designs that are expected to operate at ever higher metal temperatures. Therefore, future experimental work is concentrated on methods for improving dwell fatigue performance through surface engineering and alloy chemistry modification to improve grain boundary properties. Areas of concentration for future work will be the investigation of near surface stress reductions through Low Plasticity Burnishing. The authors also realize that the Kt 2 and Kt 3 geometries used in this study are not true representations of stress gradients in turbine disk attachments. The Kt 2 specimen is the least appropriate since the background stresses are higher than expected in an actual disk attachment. Since the stress gradient is a significant driver, future tests will use a specimen geometry and loading conditions that more closely represents the surface and background stresses of current turbine disk attachment designs. Future analytical work is concentrated on using integrated computational materials engineering (ICME) tools to better understand the nature of Alloy 10 grain boundary oxidation. The ICME approach will then be used to investigate methods such as chemistry and processing modifications to 
mitigate the deleterious effect of grain boundary oxidation on dwell fatigue life.

\section{References}

1. D. Rice, P. Kantzos, B. Hann, J. Neumann, and R. Helmink, "P/M Alloy 10 - A $700^{\circ} \mathrm{C}$ Capable Nickel Based Superalloy for Turbine Disk Applications,” Superalloys 2008, ed. Reed et al., (Warrendale, PA: The Minerals, Metals and Materials Society, 2008), 139-146.

2. M. Nathal "NASA and Superalloys: A Customer, A Participant, and Referee," Superalloys 2008, ed. Reed, et al, (Warrendale, PA: The Minerals, Metals and Materials Society,, 2008), 13-19.

3. Kim, Tae-Won, et. Al. "Continuum Damage MechanicsBased Creep-Fatigue-Interacted Life Prediction of NickelBased Superalloy at High Temperature," Scripta Materialia 57, (Elsevier, 2007), 1149-1152.

4. A. Karabela, et. Al. "Effects of Cyclic Stress and Temperature on Oxidation Damage of a Nickel-Based Superalloy," Materials Science and Engineering A 528, (Elsevier, 2011), 6194-6202.

5. T. Gabb, J. Telesman, P. Kantzos, "Effects of Temperature on Failure Modes for a Nickel-Base Doisk Superalloy,” Journal of Faiulure Analysis and Prevention, (ASM Int., 2007), 5665.

6. L. Ma, K. Chang, "Identification of SAGBO-Induced Damage Zone Ahead of Crack Tip to Characterize Sustained Loading Crack Growth in Alloy 783,” Scripta Materialia 48, (Pergamon, 2003), 1271-1276.

7. L. Ma, K. Chang, S. Mannan, “Oxide-Induced Crack Closure: An Explanatio for Abnormal Time-Dependent Fatigue Crack Propagation Behavior in Inconel Alloy 783," Scipta Materialia 48, (Pergamon, 2003), 583-588.

8. A. Hieber, H. Merrick, "High Temperature Powder Metallurgy Superalloy with Enhanced Fatigue and Creep Resistance,” U.S. Patent 6,969,431, November 2005

9. T. Gabb, J. Gayda, J. Telesman, "Scatter in Life for Dwell Fatigue of a Disk Superalloy", NASA Glenn Research Center, MS\&T07, Detroit, MI September 19, 2007.

10. Y. Jiang, "On the Study of the Creep Damage Development in Circumferential Notch Specimens," Computational Materials Science 38, (Elsevier, 2007), 653-659. 